\title{
Please call my contact person: mobile devices for a rescue mission during an emergency
}

\author{
Sunday Adewale Olaleye \\ Department of Marketing, Management and International Business, University of Oulu, Oulu, Finland \\ Ismaila Temitayo Sanusi \\ School of Computing, University of Eastern Finland, Joensuu, Finland \\ Richard Osei Agjei \\ Department of Medicine, School of Public Health, Imperial College London, UK, and \\ Frank Adusei-Mensah \\ Institute of Public Health and Clinical Nutrition, University of Eastern Finland, Kuopio, Finland
}

\begin{abstract}
Purpose - Drivers, travellers/tourists, pedestrians, paramedical officers, road safety officers, police officers and other security agencies in emergency times in developing countries are often challenged. The purpose of this paper is to explore the intervention of a quick mobile contact called "My Contact Person" (MCP) during such emergencies.

Design/methodology/approach - This study used a quantitative research method to collect data. The research tool is a researcher-made questionnaire with items developed using the five innovation dimensions and domestication. The data was analyzed with SmartPLS 3.0 software. The reliability values were above the postulated demarcation of 0.7 , while the average variance extracted conforms to the norm of 0.5 . The study participants were mobile phone users who own and use a mobile phone. Owing to the study's nature, a simple random sampling technique was used to appraise 196 respondents across Nigeria's demography.

Findings - The results show that the mobile users in a developing context are willing to observe "MCP's" efficacy before they try to appropriate it to theirdaily lifestyle. Further, "MCP's" compatibility with the telephone useris an antecedent of its relative advantages over theexisting telephone lists. The results reveal that the respondents perceived integrating and adapting "MCP" to their daily lives as a complicated process. In this study, most participants did not regard observability and trialability as a means of appropriating MCP to their daily lifestyle.

Research limitations/implications - This paper's findings' generalizability is limited because the present study was conducted using two higher education institutions (HEI) with a relatively small sample in Nigeria. Probing MCP domestication in more institutions and other communities, as significant communities' aside HEI use mobile phones will increase our research findings' generalizability. A parallel investigation of a range of developed and developing countries should be explored to ascertain mobile phone users' perceptions across context.

Practical implications - This study has several implications for citizens, especially in the developing world. MCP will provide quick contact opportunities to loved ones of the traumatized, saving lives by significantly avoiding worry, fear, anxiety and depression. MCP also has the potential of increasing input needs to be undertaken to accelerate the appropriate use of digital technology by health-care consumers, including enhancing education and technological literacy and providing access to low-cost digital technology.

Originality/value-“MCP" will be aquickintervention fordrivers, travellers/tourists, pedestrians, paramedical officers, road safety officers, police officers and other security agencies in the time of emergency. For the managers, the relative advantage is the preferable factor to create awareness for "MCP", while observability needs more effort to persuade the mobile phone users to accept and use MCP.
\end{abstract}

Keywords Innovation, Emergency, mHealth, Mobile device, Domestication, My contact person

Paper type Research paper

\section{Introduction}

The capabilities of digital communication technologies to create, store, retrieve and transmit information have the potential to enhance health-care delivery (Odendaal et al., 2015). The integration of mHealth into current health systems

is considered mainly in several research works (Labrique et al., 2013), not to mention low and middle-income settings. In Africa, the most advanced infrastructure is the mobile phone, which towers above water and potable roads, with most households, especially those in rural communities possessing mobile phone technologies and services while lacking access to good pipe-borne water (World Bank, 2017). There are significant constraints of necessary infrastructure and resources and shortages of health professionals in rural areas (Beratarrechea et al., 2017), affordable, effective and available mHealth or mobile health interventions (Beratarrechea et al., 2014) have 
been progressively adopted. The potential of using digital technologies to improve and support healthcare solutions (Odendaal et al., 2015) has been established. Health promoters also use media platforms and mobile devices to control behaviours, such as smoking, alcohol consumption, exercise and sexual behaviours (Laakso, 2011). Mobile technology adoption models such as the Unified Theory of Acceptance and Use of Technology (UTAUT) and Technology Acceptance Model (TAM), which are developed, needs improvement.

Significantly, mobile phone application brings along with it some difficulties, which include security and privacy of information, perceived usefulness, ease of use and amusement tends to impact an individual's intentions of acceptance and adoption (LorenzoRomero et al., 2011). Studies, however, show that privacy confidence and security concern of mobile device positively affect the experience of users (Olaleye et al., 2017; Olaleye et al., 2018; Olaleye et al., 2020). Other drawbacks of acceptance and use of mobile technology include the effect of age on usage and users' needs. This difference between younger and older adults seems to be especially relevant concerning mobile devices (Roque and Boot, 2018) although it is also present in the management of computers and the internet. In summary, these challenges create obstacles to quality health care.

Though mobile phone applications are used in different health-care areas for different purposes (Zhang, 2018), there are still other untapped areas where mobile phones could be applied. One such area is to easily use a mobile phone of someone in tragic emergencies to reach out to ones chosen as "my contact person" (MCP). During emergencies like fatal accidents, natural disasters and other traumatic situations, particularly in Nigeria, loved ones go through anxiety, worry and fear leading to depression owing to the communication gap. Depression is a major public health challenge (Garnefski and Kraaij, 2018). Road accident rates are increasing, especially in developing and underdeveloped countries and millions of lives are lost annually (Bun, 2012; Onyemaechi and Ofoma, 2016; Anebonam et al., 2019). Sub-Saharan Africa is the global capital for road traffic deaths (Kazeem, 2019). Death and injuries resulting from traffic crashes remain a serious problem globally, and current trends suggest it will continue in the foreseeable future (WHO, 2018). However, this can be reduced through an approach that ensures timely access to contact person and professional emergency care, especially in developing countries.
MCP's introduction has a tremendous potential to promote health and deal with anxiety, fear and depression during emergencies and traumatic situations for individuals and communities worldwide, particularly in Africa. The health-care shortcomings in many African countries mean that those who survive traffic accidents have no guarantee of adequate postcrash care (Kazeem, 2019), which is why MCP should be considered for adoption. Most fatality cases in Africa in times of emergencies result from lack of quick access to loved ones who can readily donate blood or owing to lack of enough blood banks or make a financial commitment for treatments to commence because of the cash and carry system. According to WHO (2018), the proportion of patients who die before reaching a hospital in low-income countries is over twice comparatively to high-income countries. In some developing countries where the cash and carry system for health care providers is still practised, the presence of relatives or contact persons of the traumatized is crucial for providing better services and survival. Quick contact with loved ones of the traumatized is vital in saving thousands of lives, especially individuals and families, from the significant avoidable worry, fear, anxiety and depression hence the drive for MCP. The proposal of the idea such MCP also has the potential of increasing input needs to be undertaken to accelerate the appropriate use of digital technology by health-care consumers, including enhancing education and technological literacy and providing access to low-cost digital technology.

This study explores the intervention of a quick mobile contact called "MCP" during emergencies and that mobile phone users in the developing world are willing to adopt MCP. The present study starts the discussion on the adoption process in the Nigerian context using Nigerian samples. The study is divided into five parts. Section 1 gives an overview and introduces the concept of MCP. Section 2 synthesizes relevant literature, while Section 3 explores the appropriate methodology for the study. Section 4 presents the result, and Section 5 displays the discussion and limitations and provides suggestions for future research.

\section{Diffusion of Innovation and theory of domestication}

Diffusion is widespread of technology or the adoption of widespread technology Vargo et al. (2020). Also, it is the mechanism by which an innovation is disseminated via some avenue over time among the social system, while innovation in this study is an idea perceived by individuals or societies as new (Robinson, 2009). An appropriate understanding and evaluation of the right innovation 
parameters are essential to ascertain the probability of up taking such ingenious ideas towards health promotion, health education and health-care delivery. There is a rethinking of the innovation process and recent studies geared towards dynamic, inclusive, integrative innovation diffusion and to corroborate this proposition, Vargo et al. (2020) developed a framework that divides the conceptions of technology angle of innovation from the processes of its diffusion and adoption. Inferring from the studies of Kleinaltenkamp et al. (2012) and Vargo et al. (2020) all the actors involved in MCP are resource integrators who cocreate phenomenologically while MCP diffusion is a critical part of the innovation processes. Besides, Dayyala et al. (2020) integrates innovation diffusion models based on internal, external and bass diffusion and founds that International Financial Reporting Standards (IFRS) diffusion is possible through external influence with vertical communication, through internal influence in respect of imitation and interpersonal communication across the borders. This result also established the dynamism and inclusiveness of innovation diffusion.

Roger's diffusion of innovation has been widely used by the researchers globally because it is a multidisciplinary scale. Recent studies by Wang and Lai (2020) focussed on innovation diffusion of two-sided mobile payment platforms and give an understanding of diffusion dynamics that can assist firms in evaluating risk scenarios and design their policies. Likewise, Yuen et al. (2020) examined the determinants of public acceptance of autonomous vehicles with innovation diffusion perspective and found the full mediation of innovation diffusion variables by value. Similarly, Pinho et al. (2020) applied innovation diffusion theory to the electronic learning process and identified the factors that influence the use of Moodle (learning management systems) in the academic context. The use of innovation diffusion theory is increasing and giving is impactful and contributes to the choice of the theory in this research. This study selects Everett Rogers' diffusion of innovation and domestication theory as the primary theoretical foundation for the conceptual framework under consideration. In this study, the innovation examined consisted of "MCP". In health-care context, Dearing and Cox (2018) described diffusion as a social process that occurs among people in response to learning about an innovation such as a new evidence-based approach for extending or improving health care. Depatie and Bigbee (2015) used innovation diffusion in health-related studies. According to Rogers and Shoemaker (1983), the acceptance rate of innovation depends on the innovation's quality or attributes.

\subsection{Relative Advantage}

Relative advantage talks about the degree to which innovation or idea is considered as been superior to an existing idea or innovation (Rogers, 2003). Relative advantage deals with the degree to which an adopter perceives an innovation as being better than its precursor. Thus, the innovation or idea must have an advantage relative to the one been used by the individual or society.

\subsection{Compatibility}

Compatibility describes basically the degree to which an innovation is perceived as being undeviating from the extant values, previous exposures, and needs of potential adopters (Rogers, 2003). This implies that any idea or innovation introduced to an individual or society must be consistent with their existing values and be a potential solution to their needs.

\subsection{Complexity}

Complexity describes fundamentally the degree to which an innovation is considered as challenging to comprehend and adopt (Rogers \& Shoemaker, 1983). The more complex an innovation is or vague an idea is the lower the degree of acceptance and use therefore, needed steps should always be taken to simply promote the innovation or idea for better understanding and ease of use.

\subsection{Trialability}

Trialability pertains to "the degree to which an innovation may be experimented with on a limited basis" (Zhang, 2010). It is obvious that when innovation or idea is being disseminated might be experimented with before adoption by individuals or society. It usually demonstrates how, why and at what rate and innovation or idea permeates through individuals or communities.

\subsection{Observability}

Observability is "the degree to which the sequel of innovation or idea are observable to others" (Rogers, 2003). Notably, the correlation between the strong diffusion of innovation and the individuals or societies core values, model, expectations, and behaviours. This presupposes that innovations or ideas that individuals or communities discover to possess a more relative advantage, compatibility, trialability, observability and less complexity are highly probable to be embraced and endorsed more rapidly. In the light of the above-mentioned characteristics, it is evident how much an innovation relies on its community, organisation, or system to be implemented successfully and relative advantage, compatibility and complexity have been proven to be the most significant factors in influencing decision making by individuals or communities adopting an innovation or idea. Notwithstanding, the difference in perception of potential adopters of these characteristics contributes significantly to the different rate of adoption by individuals and societies, therefore, a considerable comprehension of the impact of these innovation diffusion characteristics on any innovation since they impact the acceptance of individuals or communities. 


\subsection{Domestication}

Domestication defines the mechanism through which its users adopt innovations or ideas. It entails the integration of the innovation or idea into a daily routine and adapted to everyday habitude, the potential adopter and its setting transit and adapt consequently and the adoptions feedback into innovation mechanisms in different settings impacting new technologies and services (Silverstone \& Hirsch, 1992). Also, Baym, (2015) argues that domestication entails three stages; at the beginning inconceivable and unusual, then obtains the ability to produce greatness and panic and are then so popular and normal as to be unreal. In simple terms, the three stages can be summarised as euphoria, moral panic, and adoption, which is often integrated into health, economic, social relationships and settings by employing the evidence obtained.

\subsubsection{Research model and hypotheses}

Subsection 2.6.1 reveals the research model and hypotheses based on Rogers' diffusion of innovation and domestication theories that guided the study. The review suggests seven hypotheses for this study (Figure 1).

\section{Hypotheses development.}

Relative advantage and domestication. The greater the perceived relative advantage of $\mathrm{MCP}$, the more rapid mobile phone users are likely to domesticate it, enabling the users to adopt its use. It can be concluded that the user group's perception and needs will influence their decision to domesticate MCP.

Compatibility and relative advantage. When MCP fits with the user's life situation and needs, it would be compatible, and therefore, it would be preferred over alternative modes. For example, MCP's relative advantage mirrors the users' acknowledgment that

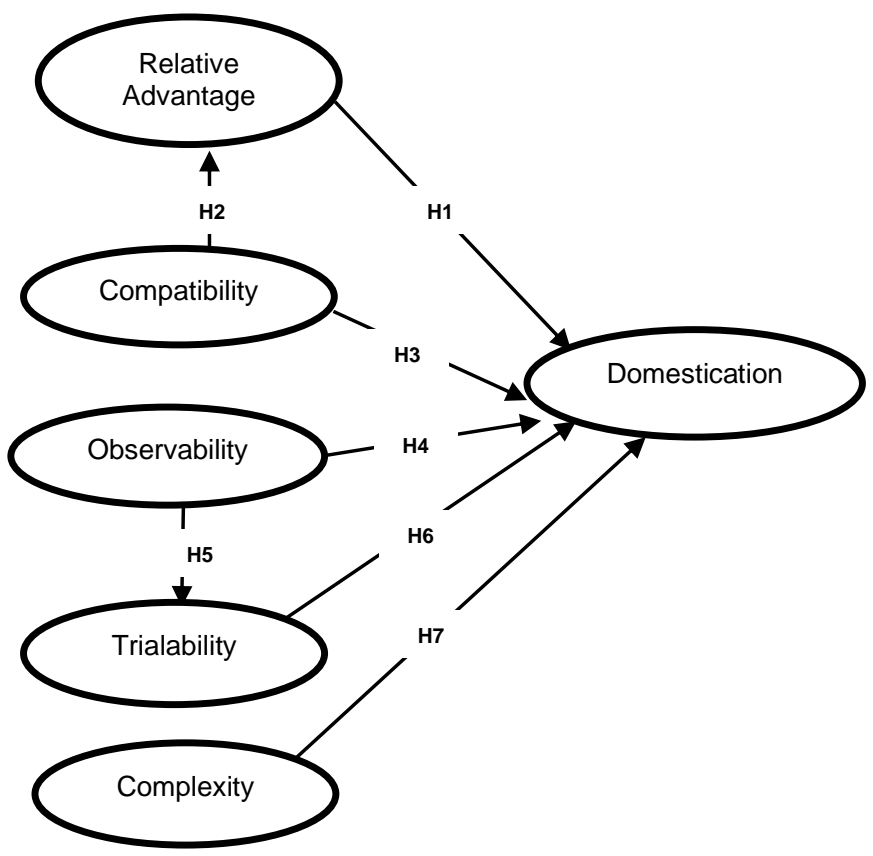

Figure 1: My Contact Person Framework and Tested Hypotheses

this new social connection method provides certain advantages over the status quo. Therefore, it can be explained that if MCP fits into the users' needs, it will be advantageous, which will serve as a pointer for domestication.

Compatibility and domestication. Previous studies found a positive relationship between compatibility and people's adoption of new information technology (Zhang et al., 2008). MCP is, therefore, one of a series of steps in domesticating Information and Communication Technologies (ICTs) using mobile phones. It can be deduced from the above that innovation will be domesticated if it fits into users' needs. We assume users' compatibility perception of using MCP will affect its domestication.

Observability and domestication. The process of domestication includes making ICTs acceptable and familiar or rejecting them. Umble (1994) posits that understanding ICT rejection can tell a researcher as much about ICT as acceptance. As visibility stimulates peer discussion of a new idea, as friends and neighbours of an adopter often request innovation-evaluation information about it (Zhang, 2010), it is expected to affect the new idea's domestication.

Observability and trialability. Observability positively affects user attitude. If innovation is visible and communicated, then the users should experiment with it. For this study, it means that the visibility of MCP will determine its trialability. It is, therefore, assumed that users' perception of MCP observability would affect its trialability.

Trialability and domestication. An innovation that is triable represents less uncertainty to the individual, considering it for adoption, who can learn by doing (Zhang, 2010). It is expected that the more triable and innovation such as MCP, the more it gets domesticated by the users, which suggests that the perception of trialability will affect MCP domestication.

Complexity and domestication. Complexity may lead users to misunderstand the function of the technology. In this study, MCP may not be domesticated by users if they fail to 
understand the advantages of using it owing to complexity. As Hardgrave et al. (2003) said, complexity negatively influenced perceived use and no direct effect.

In this study, the innovation examined consisted of "MCP", which depends on the following hypotheses quality or attributes.

Relative advantage as a predictor of domestication:

H1. The perception of relative advantage will positively influence the domestication for MCP.

Compatibility as a predictor of relative advantage:

H2. The perception of compatibility will positively influence the relative advantage of MCP.

Compatibility as a predictor of domestication:

H3. The perception of compatibility will positively influence the domestication for MCP.

Observability as a predictor of domestication:

H4. The perception of observability will positively influence the domestication of MCP.

Observability as a predictor of trialability:

H5. The perception of observability will positively influence the trialability of MCP.

Trialability as a predictor of domestication:

H6. The perception of trialability will positively influence the domestication of MCP.

Complexity as a predictor of domestication:

H7. The perception of complexity will positively influence the domestication for MCP.

\section{Methods}

\subsection{Research design, questionnaire development, sampling and data collection.}

Data were specifically gathered from the students of University of Ibadan and Kogi state college of education, both in the southern and northern part of Nigeria respectively. Respondents comprised of students and other professionals who are contacted in the institutions, however, students form the dominant respondents. Based on seven Likert scale response mode, they were asked questions on their use of mobile device for domestication especially in terms of social connections and how to make contacts in times of eventualities based on a simple random sampling technique was employed to appraise 196 university respondents. Partial least square structural equation modelling and importance-performance analysis were used to analyse the MCP data based on innovation characteristics and domestication.

The survey consists of two parts. The first part includes the background questions of the respondents; the second part deals with more specific questions in relation to the participant's perception regarding the application of MCP as a solution to emergency situations, its knowledge, acceptance and use. In the questionnaire, the seven-point Likert scale was used ranging from strongly disagree (1) to strongly agree (7). These questions intend to examine the domestication of MCP as a resultant effect exploring the effect of five innovation dimensions.

The demographic characteristics of the respondents sampled include their age, gender, education, phone ownership, marital status, tribe, occupation and the brand of phones they possess. Table I, reveals the range of age in years. It can be deduced that the perspective of a set of age group is sampled with less contribution from other arrays of the age group that are few in numbers. More males $(54.6 \%)$ partake in the study than their female $(45.4 \%)$ counterparts which show no bias towards any gender. Almost all the participants surveyed are educated, that is $99.3 \%$. This shuts out the uneducated mobile phone users as the devices are not only owned and used by only educated users. Majority of the respondents are high school/diploma students (68.6\%) and followed closely by bachelor's degree holders $(21.6 \%)$. Student dominance in the sample is as a result of the survey distributed in an academic environment.

MCP is an emerging study in the context of Africa because it probes into the family affinity and social connection in a communal and collective society. The study infers from the extant studies that have used SmartPLS 3.0 extensively (Adhikari, 2018) and used partial least square structural equation modelling to analyse the MCP data based on innovation characteristics and domestication. To explore the MCP data further, the study conducted importanceperformance analysis (IPA) to compare the performance and importance levels of relative advantage, compatibility, observability, trialability, complexity as a predictor of target construct of domestication. The study utilised SmartPLS because of its robust algorithms for a reflective model and the uniqueness of IPA insights. SmartPLS has been subjected to criticisms in the area of model fit but its drastic transformation and easy-to-use interface are advancing the use of the statistics software for research (Zhang, Guo \& Chen, 2008; Umble, 1994; Hardgrave, et. al., 2003; Adhikari, 2018; Olaleye, et. al, 2018). 


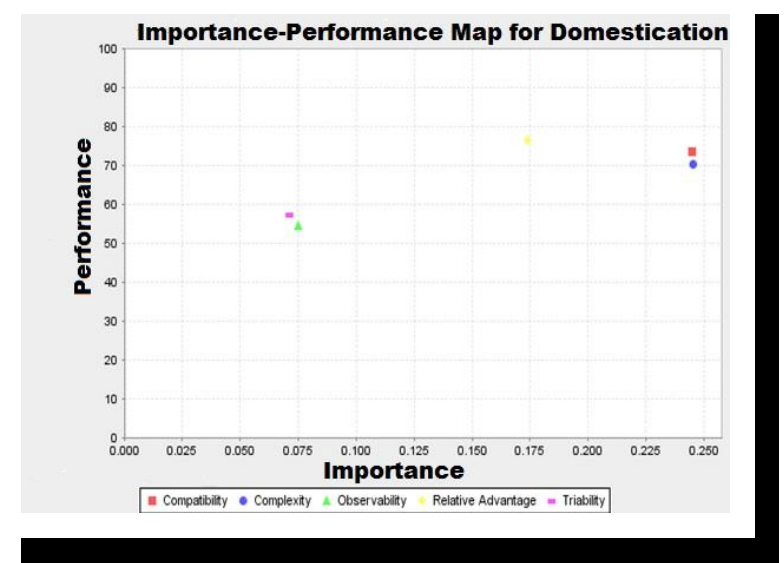

Figure 2: Importance-Performance Map for Domestication

\section{Results}

The study utilized six connected variables based on the reviewed literature to explore the effect of five innovation dimensions on the domestication of MCP. The preliminary analysis conducted shows the connectivity of items with the assigned construct and compare the result against the existing rule of thumb. The items that loaded below the threshold of 0.5 were removed and the remaining items (0.797 - 0.907) were above the 0.5 (Hair, 2017; Hox \& Bechger, 1998).

According to (do Nascimento, et. al., 2016), examination of the data reliability, discriminant and convergent validity are very important. The composite reliability result passed the quality criteria test and all the reliability values were above the postulated demarcation of 0.7 while the average variance extracted conforms to the norm of 0.5 (Barclay, et. al., 1995).

In accordance with Barclay, et. al., (1995) postulation, the results are discriminant and convergent valid (Table II). In the same manner, Figure 2 showcase the result of importance-performance with the relative advantage of MCP as the highest performing variable $(76.42 \%)$ while observability records the lowest performing construct with $(54.59 \%)$. Besides, both complexity and compatibility are the most top important variables with (0.25) unstandardized total effects while trialability is the less critical construct in MCP study. This is an indication that a one-point increase of relative advantage performance would lead to an increase of the performance of the key target construct (domestication) by the size of the total effect. The MCP domestication would increase by a value of (0.17) total effects value. The closer the performance of a latent variable to one hundred per cent (100\%), the higher its performance. Ringle \& Sarstedt, (2016) recommends importanceperformance map analysis for more insight.
Table 1. Demography Characteristics of the Respondents

\begin{tabular}{|c|c|c|c|}
\hline Variable & Classification & Frequency & Percentage \% \\
\hline \multirow[t]{5}{*}{ Age } & $<17$ & 48 & 25.3 \\
\hline & $18-25$ & 121 & 63.7 \\
\hline & $26-35$ & 6 & 3.2 \\
\hline & $35-45$ & 9 & 4.7 \\
\hline & $>45$ & 6 & 3.2 \\
\hline \multirow[t]{2}{*}{ Gender } & Male & 106 & 54.6 \\
\hline & Female & 88 & 45.4 \\
\hline \multirow[t]{5}{*}{ Education } & High School/Diploma & 105 & 68.6 \\
\hline & Bachelor's degree & 33 & 21.6 \\
\hline & Master's Degree & 13 & 8.5 \\
\hline & $\mathrm{PhD}$ & 1 & .7 \\
\hline & No Formal Education & 1 & .7 \\
\hline \multirow[t]{3}{*}{ Phone Ownership } & Yes & 156 & 83.9 \\
\hline & No & 30 & 16.1 \\
\hline & Don't Now & & \\
\hline \multirow[t]{3}{*}{ Marital Status } & Single & 161 & 93.6 \\
\hline & Married & 10 & 5.8 \\
\hline & Others & 1 & .6 \\
\hline \multirow[t]{5}{*}{ Tribe } & Yoruba & 148 & 85.1 \\
\hline & Igbo & 19 & 10.9 \\
\hline & Hausa & 2 & 1.1 \\
\hline & & 4 & 2.3 \\
\hline & Others & 1 & .6 \\
\hline \multirow[t]{5}{*}{ Occupation } & Self-employed & 52 & 31.3 \\
\hline & Student & 104 & 62.7 \\
\hline & Civil servant & 5 & 3.0 \\
\hline & Private sector & 4 & 2.4 \\
\hline & Others & 1 & .6 \\
\hline \multirow[t]{6}{*}{ Phone Brand } & Nokia & 65 & 39.9 \\
\hline & Samsung & 29 & 17.8 \\
\hline & Apple & 6 & 3.7 \\
\hline & HTC & 8 & 4.9 \\
\hline & Techno & 40 & 24.5 \\
\hline & Blackberry & 15 & 9.2 \\
\hline
\end{tabular}

Table 2. Latent Variable Correlations

\begin{tabular}{ccccccc}
\hline & COM & CPY & DOM & OBS & RA & TRY \\
\hline COM & $\mathbf{0 . 8 6 1}$ & & & & & \\
CTY & 0.375 & $\mathbf{0 . 8 9 6}$ & & & & \\
CON & 0.486 & 0.522 & $\mathbf{0 . 8 5 6}$ & & & \\
OBS & 0.416 & 0.401 & 0.392 & $\mathbf{0 . 8 4 6}$ & & \\
RA & 0.610 & 0.283 & 0.445 & 0.365 & $\mathbf{0 . 8 5 5}$ & \\
TRY & 0.442 & 0.498 & 0.430 & 0.670 & 0.260 & $\mathbf{0 . 8 7 4}$ \\
\hline COM = Compatibility, CPY= Complexity, DOM= Domestication, \\
OBS= Observability, RA = Relative Advantage, TRY= Trialability
\end{tabular}

Table 3: Construct reliability, Validity and Coefficient of Determination

\begin{tabular}{ccccccc}
\hline & COM & CPY & DOM & OBS & RA & TRY \\
\hline CR & 0.891 & 0.804 & 0.883 & 0.890 & 0.866 & 0.895 \\
AVE & 0.892 & 0.733 & 0.716 & 0.730 & 0.764 & 0.741 \\
rho_A & 0.761 & 0.818 & 0.813 & 0.814 & 0.705 & 0.829 \\
R2 & & $\mathbf{0 . 3 9 3}$ & & $\mathbf{0 . 3 6 9}$ & $\mathbf{0 . 4 4 6}$ & \\
\hline
\end{tabular}




\subsection{Tested Hypotheses}

The study proposed seven (7) hypotheses based on the path coefficient of the latent variables (Table 4). First, the study hypothesised that the perception of relative advantage would positively influence the domestication for my contact person. That is, the relative advantage of a mobile device with the inclusion of my contact person in the telephone contact list will be appropriate by the mobile phone users as they integrate MCP into their daily living. The study hypothesised that (relative advantage $\rightarrow$ domestication $\beta=$ 0.20 and $t=2.17$ and the result is significant at $p$ 0.032) with an effect size of 0.041 while (compatibility $->$ relative advantage $\beta=0.61$ and $t=10.62$ and the result is significant at p 0.000) with an effect size of 0.593 and (compatibility -> domestication $\beta=0.39$ and $\mathrm{t}=3.77$ and the result is significant at $\mathrm{p} 0.000$ ) with an effect size of 0.131 . The mobile phone users want to know the tangibility of MCP and the study hypothesized that (observability -> domestication $\beta=0.04$ and $t=0.57$ and the result is significant at $\mathrm{p}$ 0.572) with an effect size of 0.01 and (observability $\rightarrow$ trialability $\beta=0.67$ and $t=17.13$ and the result is significant at $\mathrm{p} 0.000$ ) with an effect size of 0.81 . The study explores the intention of mobile users to test MCP and hypothesized that (trialability $->$ domestication $\beta$ $=0.10$ and $t=1.25$ and the result is significant at $\mathrm{p} 0.202$ ) with an effect size of 0.009 . Similarly, the study examines how difficult it will be for the mobile users to understand MCP (complexity $\rightarrow$ domestication $\beta=0.17$ and $t=2.04$ and the result is significant at p 0.042) with an effect size of 0.027. Observability as a predictor of trialability of domestication of MCP has the highest significant t-test value while complexity as a predictor of domestication recorded the lowest t-test value. Hypotheses 1-3, 5 and 7 are supported while hypotheses 4 and 6 were rejected because they did not reach the threshold of 1.96 . Observability path coefficient with trialability has the highest effect size while observability path coefficient with domestication has the lowest effect size. Hair, et. al., (2017) observed that $f^{2}$ and other metrics are less reported in extant studies and recommend $0.35,0.15$ and 0.02 as rule of thumb for strong effects, moderate and weak effect size. The $f^{2}$ reported reflect weak and strong effect size. Table 4 showcase the determination of the coefficient of trialability with $44.6 \%$, domestication with $39.3 \%$ and $36.9 \%$. In the line of thought with Hair, et. al., (2017), the acceptable R2 depends on the context of the study. Since MCP is a relatively new concept, more latent variables than the one utilized in this study will be needed to ascertain the adoption, use and continuous intention of MCP.

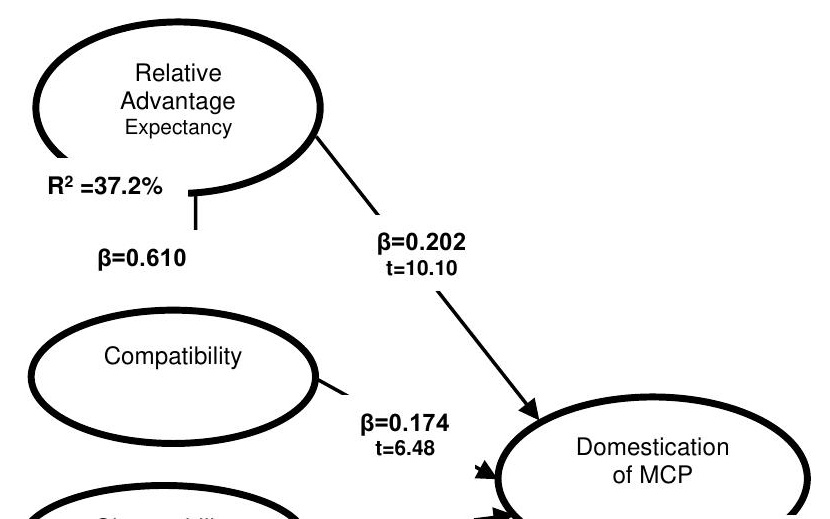

Figure 3: Results of PLS Analysis

Table 4: Standardized path coefficients and corresponding hypothesis results

\begin{tabular}{cccllc}
\hline HYP & Path & $\begin{array}{c}\text { Sample } \\
\text { Mean }\end{array}$ & $\begin{array}{c}\text { Standard } \\
\text { Deviation }\end{array}$ & T-Test & $\begin{array}{c}\text { HYP } \\
\text { Confirmed }\end{array}$ \\
\hline H1 & COM->DOM & 0.174 & 0.085 & 2.04 & Yes \\
H2 & COM -> RA & 0.610 & 0.057 & 10.62 & Yes \\
H3 & OBS->DOM & 0.041 & 0.073 & 0.57 & No \\
H4 & OBS->TRY & 0.670 & 0.039 & 17.13 & Yes \\
H5 & RA -> DOM & 0.202 & 0.093 & 2.17 & Yes \\
H6 & TRY->DOM & 0.109 & 0.087 & 1.25 & No \\
H7 & CTY->DOM & 0.329 & 0.087 & 3.77 & No \\
\hline
\end{tabular}

\section{Discussion}

This study explored the intervention of a quick mobile contact called "MCP" during emergencies. The results show that the mobile users in a developing context are willing to observe "MCP's" efficacy before they try to appropriate it to their daily lifestyle. It was interesting to observe that all the results passed the quality criteria test and the reliability test. This study confirms the values being above the postulated demarcation of 0.7 (Table 2). This observation supports the belief that participants are willing to observe MCP's efficacy and appropriateness in their daily lives as they find it more reliable to impact their lifestyle. The high scores (Tables 1 and 2) show how strong the literature supports the observation (Barclay et al., 1995). The observed average variance extracted in the present study (Tables 1 and 2) also supports the rule of thumb of 0.5 (Barclay et al., 1995) and domestication of MCP. According to Barclay and colleagues' (Barclay et al., 1995) postulation, 
the results are discriminant and convergently valid (Table 1), and it strongly supports the domestication of MCP.

Similarly, in Figure 2 and Table 2,MCP's relevance could be observed with a high importance-performance relative advantage (RA) of MCP with the highest performing variable of $76.4 \%$. This observation indicates that MCP fits well with the user's life situation and needs, and it would be compatible and preferred by users over alternative modes. On the contrary, observability records the lowestperforming construct with the lowest-performing ability previously identified to affect users' attitudes to try a new technology positively. In the present study, about $54 \%$ of the users will try MCP innovation if it becomes visible or communicated to them, suggesting that MCP's trialability hinges on its visibility. Besides these, both complexity and compatibility are among the top-most important variables towards MCP domestication with 0.25 unstandardized total effects, while trialability is the less critical construct in MCP domestication. This direction indicates that a one-point increase in relative advantage performance would increase domestication performance by the size of the total effect (Ringle and Sarstedt, 2016). The MCP domestication would increase by a value of (0.17) total effects value. The closer the latent variable's performance to $100 \%$, the higher its performance (Ringle and Sarstedt, 2016).

Further, "MCP's" compatibility with the telephone user is an antecedent of its relative advantages over the existing telephone lists. The results reveal that the respondents perceived integrating and adapting "MCP" to their daily lives as a complicated process. In this study, most participants did not perceive observability and trialability to appropriate "MCP" to their daily lifestyle. This unperceived scenario may be owing to technology use skepticism and resistance. As an insight to the managers, the relative advantage is the preferable factor to create awareness for "MCP," while observability needs more effort to persuade the mobile phone users to accept and use "MCP." On the other hand, the complexity and compatibility factors are the most vital component of educating mobile phone users to integrate "MCP" into their lifestyle.

Innovation is good for behavioural change and development but not with challenges. The first innovation challenge is the inability of individuals in a social system to adopt innovations at the same time. Secondly, the attitudes of individuals to a particular innovation differ. Considering these challenges, Rogers classified innovation adopters into five categories based on the gap of adoption. According to Rogers, the hierarchy of adopters start with Innovators which account for $2.5 \%$, followed by early adopters with $13.5 \%$, early majority with $34 \%$ and tally with late majority with $34 \%$ and lastly with laggards with $16 \%$. The adopter categorization of innovativeness is symmetrical. This frequency distribution indicates the adopter's awareness of their needs for innovation, their decision to adopt the innovation, their initial use of the innovation and after their initial experience, their desire to continue to use the innovation. Above categorization, this study integrates the five main factors that influence the adoption of innovation with domestication theory, then classified, relative advantage, compatibility, complexity, trialability and observability as independent variables that predict domestication as the dependent variable. The innovation influencer predicts how innovation becomes part of the everyday life of the adopters.

This study contributes to the literature of mobile technology in three ways. Firstly, this research clearly shows five factors that are responsible for innovation relative advantage, trialability and domestication. These factors are relative advantage, complexity, compatibility and observability. Relative advantage has a direct relationship with domestication, while complexity has a direct relationship with relative advantage and indirect relationship with domestication. Like relative advantage, compatibility and complexity have a direct relationship with domestication, while observability has an indirect relationship with trialability. For adopters to appropriate MCP into their daily lives, the direct relationship of relative advantage, compatibility and complexity with domestication is essential.

On the other hand, the intervention of domestication is crucial for complexity and relative advantage and observability and trialability. The complexity of relative advantage can determine its relative advantage, while observability of MCP can trigger its trialability when thinking about MCP appropriateness. Secondly, this study gives an understanding of how MCP can be tamed or appropriate by its adopters into their daily lives. Thirdly, this study also shows how domestication used as a dependent variable of innovation variables which is scarce in the literature.

The study conducts importance-performance analysis, and the results show that among the five variables, compatibility top the list concerning performance and followed closely with complexity and in the aspect of importance, the two variables (compatibility and complexity) are most important in this context. The health managers should embark on rigorous advertising through the Billboard by using emotional appealing text and picture to explain the extent of the complexity of the MCP and how crucial its compatibility with adopter's lifestyle. A recent study of Olaleye et al. (2020) emphasized the importance of compatibility of online distance learning with learner's lifestyle. The study suggests that the managers should avail the opportunity of MCP to use social media advertisement to persuade the Nigerian community innovators and early adopters to observe the intervention of MCP and to try to use it. This study has the potential of replication in other Africa countries apart from Nigeria.

\subsection{Conclusion}


We explored the intervention of a quick mobile contact called "MCP" during emergencies in the light of the seven hypothetical constructs. The preliminary analysis conducted shows the connectivity of the seven constructs: compatibility, complexity, domestication, observability, relative advantage and trialability towards the domestication of MCP innovation. This present study observed that compatibility significantly affected the relative advantage. Also, relative advantage, compatibility, observability, trialability and complexity significantly impact MCP innovation's domestication. In conclusion, " $M C P$ " will be a quick intervention for drivers, travellers/tourists, pedestrians, paramedical officers, road safety officers, police officers and other security agencies in the time of emergency. Its successful implementation is, however, hinged on careful consideration of the studied factors. This study is only limited to 1 country out of 54 countries in Africa. Because of this limitation, the future study should work on the results presented and replicate this study in other African countries, as African citizens have similar road use lifestyles. Comparative analysis across Africa countries will help future researchers to gain insights into mobile economic use for life-saving.

It is important to note many strengths of this article include the use of a relatively large sample size across different age groups, socioeconomic status and educational level, a careful data collection involving multi-method assessment of each observable and nonobservable variable in this research based on respondents' self-report measures and further validated by personal data collection conducted by the researcher. Again, an appropriate theoretical application in the research design and SEM use with SmartPLS version 3.0 for the various analyses. Nevertheless, this study did not overlook the possibility of some relevant limitations. Firstly, this study investigated MCP's domestication and its trajectories across different age groupings $(<17$, $18-25,26-35,35-45$ and 45 years and above).

Notwithstanding, however, the results cannot be generalized in terms of all age groupings. There was not much analysis and evaluation done on aged 45 years and above owing to the low number of respondents. This study generalizability is limited because the present study conducted using two higher education institutions (HEI) with a relatively small sample. Probing MCP domestication in more institutions and other communities, as significant communities aside HEI use mobile phones will increase the generalizability of our research findings and parallel investigations of a range of developed and developing countries. Also, the study samples reside in urban areas, our study results might not give the actual perception of rural dwellers, and future research should investigate these issues.

\section{References}

Adhikari, M., Paton, D., Johnston, D., Prasanna, R. and McColl, S.T. (2018), "Modelling predictors of earthquake hazard preparedness in Nepal", Procedia Engineering, Vol. 212, pp. 910-917.

Anebonam, U., Okoli, C., Ossai, P., Ilesanmi, O., Nguku, P., Nsubuga, P. and Oyemakinde, A. (2019), "Trends in road traffic accidents in Anambra state, South Eastern Nigeria: need for targeted sensitization on safe roads", Pan African Medical Journal, Vol. 32.

Barclay, D., Higgins, C. and Thompson, R. (1995), “The partial least squares (pls) approach to casual modeling: personal computer adoption ans use as an illustration".

Baym, N.K. (2015), Personal Connections in the Digital Age, John Wiley \& Sons, pp. 44-49.

Beratarrechea, A., Moyano, D., Irazola, V. and Rubinstein, A. (2017), "mHealth interventions to counter noncommunicable diseases in developing countries: still an uncertain promise", Cardiology Clinics, Vol. 35 No. 1, pp. 13-30.

Beratarrechea, A., Lee, A.G., Willner, J.M., Jahangir, E., Ciapponi, A. and Rubinstein, A. (2014), "The impact of mobile health interventions on chronic disease outcomes in developing countries: a systematic review", Telemedicine and e-Health, Vol. 20 No. 1, pp. 75-82.

Bun, E. (2012), "Road traffic accidents in Nigeria: a public health problem", Afrimedic Journal, Vol. 3, pp. 34-35.

Dayyala, N., Zaidi, S.K.R. and Bagchi, K. (2020), "Diffusion of IFRS using innovation diffusion models", International Journal of Accounting \& Information Management, Vol. 28 No. 4.

Dearing, J.W. and Cox, J.G. (2018), "Diffusion of innovations theory, principles, and practice", Health Affairs, Vol. 37 No. 2, pp. 183-190.

Depatie, A. and Bigbee, J.L. (2015), "Rural older adult readiness to adopt mobile health technology: a descriptive study", Online Journal of Rural Nursing and Health Care, Vol. 15 No. 1, pp. 150-184.

do Nascimento, J.C.H.B. and da Silva Macedo, M.A. (2016), "Structural equation models using partial least squares: an example of the application of SmartPLSK in accounting research", Revista de Educação e Pesquisa em Contabilidade, Vol. 10.

Garnefski, N. and Kraaij, V. (2018), "Specificity of relations between adolescents' cognitive emotion regulation strategies and symptoms of depression and anxiety", Cognition and Emotion, Vol. 32 No. 7, pp. 1401-1408.

Hair, J., Hollingsworth, C.L., Randolph, A.B. and Chong, A.Y.L. (2017), "An updated and expanded assessment of PLS-SEM in information systems research", Industrial Management \& Data Systems, Vol. 117, pp. 442-458.

Hardgrave, B.C., Davis, F.D. and Riemenschneider, C.K. (2003), "Investigating determinants of software 
developers' intentions to follow methodologies", Journal of Management Information Systems, Vol. 20, pp. 123-151.

Hox, J.J. and Bechger, T.M. (1998), “An introduction to structural equation modeling".

Kazeem, Y. (2019), "Death rates from traffic accidents are higher in Africa than anywhere else", World economic forum, available at: www.weforum.org/agenda/2019/02/ death-rates-from-traffic-accidents-are-higher-in-africa-thananywhere-else/ (accessed 2 September 2020).

Kleinaltenkamp, M., Brodie, R.J., Frow, P., Hughes, T., Peters, L.D. and Woratschek, H. (2012), "Resource integration", Marketing Theory, Vol. 12 No. 2, pp. 201-205.

Laakso, M. (2011), "Heart in diabetes: a microvascular disease", Diabetes Care, Vol. 34 No. Supplement_2, pp. 145-149.

Labrique, A.B., Vasudevan, L., Kochi, E., Fabricant, R. and Mehl, G. (2013), "mHealth innovations as health system strengthening tools: 12 common applications and a visual framework", Global Health: Science and Practice, Vol. 1, pp. 160-171.

Lorenzo-Romero, C., Constantinides, E. and Alarcón-delAmo, M.D.C. (2011), "Consumer adoption of social networking sites: implications for theory and practice", Journal of Research in Interactive Marketing, Vol. 5, pp. 170-188.

Martínez, C. and Olsson, T. (2020), "Domestication outside of the domestic: shaping technology and child in an educational moral economy", Media, Culture \& Society.

Odendaal, W., Goudge, J., Griffiths, F., Tomlinson, M., Leon, N. and Daniels, K. (2015), "Healthcare workers' perceptions and experiences on using mHealth technologies to deliver primary healthcare services: a qualitative evidence synthesis", The Cochrane Database of Systematic Reviews, Vol. 11.

Olaleye, S.A., Sanusi, I.T. and Adepoju, B. (2018), "Model comparison of mobile retail app use and continuous use: an approach of SPSS regression", Advances in Science, Technology andEngineering Systems Journal, Vol.3 No.6,pp. 151-158.

Olaleye, S.A., Sanusi, I.T. and Oyelere, S.S. (2017), "Users experience of mobile money in Nigeria", IEEE Africon Proceedings, 2017, pp. 929-934.

Olaleye, S.A., Sanusi, I.T. and Salo, J. (2020), "Mobile customers' experience and loyalty: a study of tablet gender divergence in Finland", International Journal of Internet Marketing and Advertising, Vol. 14 No. 3, pp. 275-298.

Olaleye, S.A., Oyelere, S.S., Sanusi, I.T. and Agbo, F.J. (2018), "Experience of ubiquitous computing technology driven mobile commerce in Africa: impact of usability, privacy, trust, and reputation concern", International Journal of Interactive Mobile Technologies (IJIM), Vol. 12 No. 3, pp. 420.

Olaleye, S.A., Sanusi, I.T., Agbo, F.J. and Oyelere, S.S. (2020), "Is online distance learning compatible with student lifestyle? Examination of program content, workload and long-time usefulness", Proceedings of LACLO 2020 (XV) Latin American Conference on Learning, IEEE.

Onyemaechi, N.O.C. and Ofoma, U.R. (2016), "The public health threat of road traffic accidents in Nigeria: a call to action”, Annals of Medical and Health Sciences Research, Vol. 6 No. 4, pp. 199-204.
Pinho, C., Franco, M. and Mendes, L. (2020), “Application of innovation diffusion theory to the E-learning process: higher education context", Education and Information Technologies, pp. 1-20.

Ringle, C.M. and Sarstedt, M. (2016), "Gain more insight from your PLS-SEM results: the importanceperformance map analysis", Industrial Management \& Data Systems, Vol. 116, pp. 1865-1886.

Robinson, L. (2009), "A summary of diffusion of innovations. Enabling change".

Rogers, E.M. (2003), Diffusion of Innovations, Free Press, New York, NY.

Rogers, E.M. and Shoemaker, F. (1983), Diffusion of Innovation: A Cross-Cultural Approach, Free Press, New York, NY.

Roque, N.A. and Boot, W.R. (2018), "A new tool for assessing mobile device proficiency in older adults: the mobile device proficiency questionnaire", Journal of Applied Gerontology, Vol. 37 No. 2, pp. 131-156.

Silverstone, R. and Hirsch, E. (1992), Consuming Technologies: Media and Information in Domestic Spaces, Routledge, New York, NY.

Umble, D.Z. (1994), "The Amish and the telephone: Resistance and reconstruction", in Silverstone, R. and Hirsch, E. (Eds), Consuming Technologies: Media and Information in Domestic Spaces, Routledge, New York, NY, pp. 183-194.

Vargo, S.L., Akaka, M.A. and Wieland, H. (2020), "Rethinking the process of diffusion in innovation: a service- ecosystems and institutional perspective", Journal of Business Research, Vol. 116.

Wang, J. and Lai, J.Y. (2020), "Exploring innovation diffusion of two-sided mobile payment platforms: a system dynamics approach", Technological Forecasting and Social Change, Vol. 157, p. 120088.

WHO (2018), Global Status Report on Road Safety 2018. ISBN 978-92-4-156568-4.

World Bank (2017), "Pipe(d) dreams: water supply, sanitation, and hygiene progress and remaining challenges in Ecuador", World Bank, Washington, DC, available at: https:// openknowledge.worldbank.org/handle/10986/28223, License: CC BY 3.0 IGO 2017

Yuen, K.F., Wong, Y.D., Ma, F. and Wang, X. (2020), “The determinants of public acceptance of autonomous vehicles: an innovation diffusion perspective", Journal of Cleaner Production, Vol. 270, p. 121904.

Zhang, Y., Gravina, R., Lu, H., Villari, M. and Fortino, G. (2018), "PEA: parallel electrocardiogram-based authentication for smart healthcare systems", Journal of Network and Computer Applications, Vol. 117, pp. 10-16.

Zhang, N., Guo, X. and Chen, G. (2008), "IDT-TAM integrated model for IT adoption", Tsinghua Science \& Technology, Vol. 13, pp. 306-311.

Zhang, L., Wen, H., Li, D., Fu, Z. and Cui, S. (2010), "Elearning adoption intention and its key influence factors based on innovation adoption theory", Mathematical and Computer Modelling, Vol. 51 Nos 11/12, pp. 1428-1432. 